Acta Technologica Agriculturae 1

Nitra, Slovaca Universitas Agriculturae Nitriae, 2018, pp. 18-23

\title{
ELECTRIC PROPERTIES MEASUREMENT OF LENTIL
}

\author{
Ján NOVÁK \\ Slovak University of Agriculture in Nitra, Slovak Republic
}

\begin{abstract}
This paper contains the results of the electric properties measurement of lentil set. Electric measurements with use of these materials are of fundamental importance in relation to the analysis of quantity of absorbed water and dielectric heating characteristics. The aim of this paper was to perform the measurements of conductivity, dielectric constant and loss tangent on samples of lentil, the electrical properties of which had not been sufficiently measured. Measurements were performed under various moisture contents, and the frequency of electric field ranged from $1 \mathrm{MHz}$ to $16 \mathrm{MHz}$, using a Q meter with coaxial probe. It was concluded that conductivity, relative permittivity and loss tangent increased with an increase in moisture content, and dielectric constant and loss tangent decreased as the frequency of electric field increased.
\end{abstract}

Keywords: complex electrical permittivity; dielectric constant; conductivity; lentil

In the last years, the interest in electric properties of biological materials resulted in the engineering research in the field of agriculture. The knowledge of the physical properties of agricultural products is useful, if not essential, for the design of every agricultural machine. The research and determination of physical properties of agricultural materials has also resulted in the development of many instruments. The study of electrical properties is important for predicting the behaviour of a material in electric field or for knowledge of how the presence of material can influence the field or associated electrical circuit. Electric measurements on these materials are of fundamental importance in relation to the analysis of quantity of absorbed water and dielectric heating characteristics. The dielectric properties of materials represent an important part of electric properties. The research of electric properties is utilised in many technical applications. Measurement results are used for determination of moisture content, the surface level of liquid and grainy materials, controlling the presence of pests in seed storage, the quantitative determination of mechanical damage, and many other cases (Priatková et al., 2011). The electric properties of many biological materials have already been observed. It was discovered that the electric properties of these materials are very dependent on material moisture content. Small amounts of adsorbed water can cause large changes in electric properties of hygroscopic materials. An extensive review of the literature on dielectric properties of agricultural materials was published (Nelson et al., 2007). It includes a number of potential applications which are focused on the dielectric properties of such products. The electric properties of grains and seeds depend on their moisture content and on the frequency of electric field. The dielectric properties of grains and seeds have been explored using certain frequency ranges, as these properties were of great significance for dielectric heating applications, for moisture measurement or for process control detection (You and Nelson, 1988). The dielectric properties of the majority of biological materials vary by the frequency and temperature. In hygroscopic materials, they are also highly dependent on moisture content. Several aspects of the frequency dependence of dielectric properties have been included in the published review (Nelson et al., 2007). A study of the frequency dependence of dielectric properties of insects and grain in the frequency range from $250 \mathrm{~Hz}$ to $12 \mathrm{GHz}$ has been documented (Nelson et al., 2007). This study defines the frequency range from $10 \mathrm{MHz}$ to $100 \mathrm{MHz}$ as the most promising frequency range for selective heating of rice weevils in wheat through differential energy absorption from alternating electric field. For the more complete picture, however, similar data is necessary for the temperature dependence of dielectric properties. With recent progress in the practical application of microwave heating, a need for information on the dielectric properties of materials, to which such energy is applied, has been developed. While some information is available on the dielectric properties of grain and seed at lower frequencies (Nelson et al., 2007; You and Nelson, 1988; Lawrence et al., 1990; Kertész et al., 2015), there is a scarcity of information on these properties at microwave frequencies. Therefore, the dielectric properties of several kinds of grain and seed have been measured at a few various microwave frequencies, and the dependence on moisture content has been taken into consideration. Nelson (1991) gave a comprehensive summary of dielectric methods for measuring the moisture present in materials. Nelson (1999) discussed some methods of measuring the moisture content of soil, too. One of these methods is a dielectric method. Resultant accuracy and temperature effects were also documented by Nelson (1999). The interest in the dielectric behaviour of biological materials increased with the spread of radio frequency heating techniques. Lawrence et al. (1992) discussed in detail the application of

Contact address: Ján Novák, Slovak University of Agriculture in Nitra, Faculty of Engineering, Department of Physics, Tr. Andreja Hlinku 2, 94976 Nitra, Slovak Republic, e-mail: jan.novak1@uniag.sk 
radio frequency heating to good electrical conductors, as well as to poor electrical conductors. You and Nelson (1988) conducted a study of the dielectric constant of rice grains. They measured the dielectric constant and loss factor at the frequency range from $435 \mathrm{~Hz}$ to $1,740 \mathrm{~Hz}$ and observed that the dielectric constant of rice grains depended on density, moisture content, temperature and frequency. Bansal et al. (2016) studied the dielectric properties of rapeseed at the temperature from $20^{\circ} \mathrm{C}$ to $60^{\circ} \mathrm{C}$ and at the frequency range from $10 \mathrm{MHz}$ to $3,000 \mathrm{MHz}$. The calculated penetration depth of the electromagnetic field of rapeseed at the ISM (industrial, scientific and medical radio bands) frequencies shows that at the given moisture content and temperature, it decreases with increasing frequency. This observation provided the basic lead for the design of many instruments and application of dielectric heating to agricultural products.

\section{Material and methods}

Every material influences the electric field to which it is subjected. The relation between the parameters of electromagnetic field and properties of material is described with permittivity $\varepsilon$ and permeability $\mu$ of this material. Both parameters describe the electromagnetic properties of material. The thesis of Weir (1974) deals with the measurement of these parameters. Permittivity is a complex quantity:

$$
\varepsilon^{*}=\varepsilon^{\prime}-j \varepsilon^{\prime \prime}
$$

The real part of complex permittivity $\varepsilon^{*}$ is dielectric permittivity $\varepsilon^{\prime}$. The coefficient of imaginary part $\varepsilon^{\prime \prime}$ characterises dielectric losses. The dielectric properties of materials are generally formulated by relative complex permittivity:

$$
\varepsilon_{r}^{*}=\frac{\varepsilon^{*}}{\varepsilon_{0}}=\frac{\varepsilon^{\prime}}{\varepsilon_{0}}-j \frac{\varepsilon^{\prime \prime}}{\varepsilon_{0}}=\varepsilon_{r}^{\prime}-j \varepsilon_{r}^{\prime \prime}=\varepsilon_{r}^{\prime}(1-\operatorname{tg} \delta)
$$

where:

$\operatorname{tg} \delta=\frac{\varepsilon_{r}^{\prime \prime}}{\varepsilon_{r}^{\prime}}=\frac{\varepsilon^{\prime \prime}}{\varepsilon^{\prime}}=\frac{\sigma}{\omega \varepsilon^{\prime}}$

is the loss tangent of loss angle $\delta$; it is the angle completing to $\frac{\pi}{2}$ phase difference between voltage and current flowing through the dielectric, $\varepsilon_{0}$ is the permittivity of vacuum $\left(8.854 \cdot 10^{-12} \mathrm{~F} \cdot \mathrm{m}^{-1}\right)$. In order to measure the dielectric properties of seed samples, a resonant method has been used. This method for measuring the seed and liquid dielectric properties at a frequency range from $100 \mathrm{kHz}$ to $300 \mathrm{kHz}$ was developed by Nelson et al. (2007). The capacitance of the testing capacitor was measured by the $Q$ meter TESLA MB 560. By measuring the permittivity $\varepsilon^{\prime}$ and loss tangent $\operatorname{tg} \delta$ of testing capacitor, the real capacitor can be considered a lossless capacitor connected to active resistance in a parallel or serial configuration. The measurement goal is to determine the magnitude of capacitance and resistance of parallel or serial configuration of dielectric properties at specific frequency. The $Q$ meter was connected to the testing coaxial capacitor, which was used as a sample holder. The measurement was performed at the frequency range from $1 \mathrm{MHz}$ to $16 \mathrm{MHz}$. Relative permittivity $\varepsilon_{r}$ was calculated according to the following relations:

$$
\begin{gathered}
\varepsilon_{r}=\frac{C-C_{x}}{C_{o}} \\
C=C_{1}-C_{2}
\end{gathered}
$$

where:

C - capacitance of testing capacitor with a sample, $F$

$C_{0} \quad$ - capacitance of empty testing capacitor without any interconnector capacitance, $\mathrm{F}$

$C_{x} \quad$ - capacitance of interconnector, $F$

$C_{1} \quad$ - capacitance of tuning capacitor by resonance and by non-connection of testing capacitor, $F$

$\mathrm{C}_{2} \quad$ - capacitance of tuning capacitor by resonance and by connection of testing capacitor, $\mathrm{F}$

The resistance $R$ of testing capacitor was measured using a multimeter MASTER M830BUZ. Sample conductivity $\sigma$ was determined according to the following relation:

$$
\sigma=\frac{\ln \frac{r_{1}}{r_{2}}}{2 \pi / R}
$$

where:

$\begin{array}{ll}r_{1} & - \text { radius of outer electrode, } 0.033 \mathrm{~m} \\ r_{2} & - \text { radius of inner electrode, } 0.008 \mathrm{~m} \\ l & - \text { length of capacitor, } 0.06 \mathrm{~m}\end{array}$

Loss tangent $\operatorname{tg} \delta$ can be calculated using the following relations:

$$
\begin{gathered}
\operatorname{tg} \delta=\frac{1}{\omega R C}=\frac{\sigma}{\omega \varepsilon} \\
\omega=2 \pi f
\end{gathered}
$$

where:

$$
\begin{array}{ll}
\mathrm{f} & - \text { frequency of electric field, } \mathrm{Hz} \\
\varepsilon & - \text { sample permittivity, } \mathrm{F} \cdot \mathrm{m}^{-1}
\end{array}
$$

Measurements were carried out on two types of lentil: small-seeded and large-seeded. All samples were obtained from local shop. The origin country of samples is Canada. The impact of moisture content on dielectric constant and loss factor at the frequency range from $1 \mathrm{MHz}$ up to $16 \mathrm{MHz}$ and the impact of moisture content on conductivity were observed in this paper. The moisture content of samples was regulated by adding distilled water or by drying. Moisture content wet basis $w$ was determined according to the following relation:

$$
w=\frac{m_{1}-m_{2}}{m_{2}} 100 \%
$$

where:

$m_{1} \quad$ - mass of sample

$m_{2} \quad$ - mass of dry sample 
All measurements were performed at an air temperature of $20{ }^{\circ} \mathrm{C}$ and $60 \%$ relative humidity. Bulk density was determined according to the mass of constant sample volume.

\section{Results and discussion}

The samples are of different moisture content $w$ and bulk density $\rho$. The values of moisture content $w$ and bulk density $\sigma$ of lentil set samples are presented in Table 1 . The impacts of moisture content on conductivity, relative permittivity and loss factor are shown in Figs 1, 4, 5, and 7 ; and relative permittivity and loss factor in the function of frequency are shown in Figs 2, 3 and 6. The factors having the highest impact on these properties are also specified. The measurements indicate that lentil must be included in the most complex objects. It belongs to organic, heterogeneous, multi-component dielectrics. It was determined that the relative permittivity of lentil set decreases when the frequency of electric field increases. The highest decrease was identified at lower frequency of $3 \mathrm{MHz}$ and lower moisture content of $10 \%$. These dependences best describe the power functions. The minimal decrease can be observed at higher frequencies. This relationship is caused by the dipole moment of water molecules and probably by the orientation of charged groups of macromolecules. In this case, orientation polarisation occurs in electric field. This type of polarisation is highly dependent on frequency. Dipole macromolecules are not able to follow changes in the polarity of electric field. The values of relative permittivity increase with the increase in moisture content of samples. The power functions best describe these dependences. This effect is the consequence of a very high magnitude of water relative permittivity in comparison to other lentil components. The impact of the moisture content of samples on loss tangent in the function of frequency has a course similar to the effect of these parameters on relative permittivity. Conductivity values increase with the increase in the moisture content of samples. The power function best describes this dependence. This effect is caused by improvement of conditions for an electrolytic transport of charges by dissociated ions in damp material. The values of bulk density and relative permittivity of small-seeded lens are a little bit higher than values of large-seeded lens. The type of lentils has negligible influence on the measurement values of conductivity and loss tangent. It is known that electric properties are also related to the bulk density of material. Therefore, to ensure the definiteness of results, the bulk density values of samples have been introduced, too.

Table $1 \quad$ Values of moisture content $w$ and bulk density $\rho$ of samples

\begin{tabular}{|c|c|c|c|c|}
\hline \multicolumn{5}{|c|}{ Small-seeded lens } \\
\hline$w$ in $\%$ & 7.4 & 14.7 & 25.6 & 30.8 \\
\hline$\rho$ in $\mathbf{k g} \cdot \mathbf{m}^{-3}$ & 838 & 802 & 749 & 729 \\
\hline \multicolumn{5}{|c|}{ Large-seeded lens } \\
\hline$w$ in $\%$ & 9.1 & 15.8 & 22.1 & 29.3 \\
\hline$\rho$ in $\mathbf{k g} \cdot \mathbf{m}^{-3}$ & 806 & 718 & 661 & 632 \\
\hline
\end{tabular}

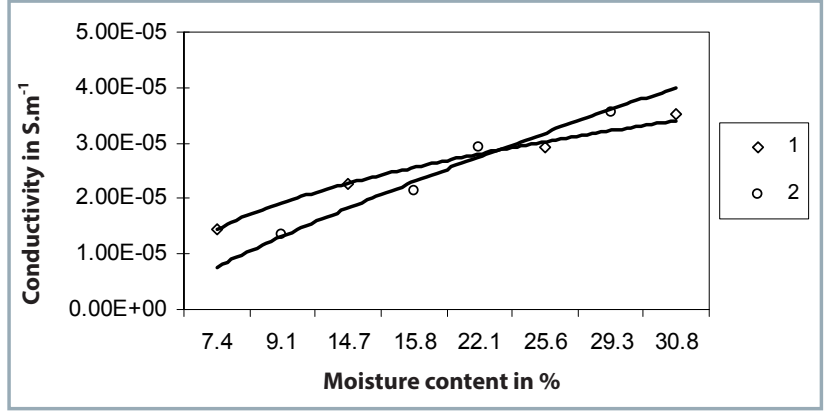

Fig. 1 Conductivity $\sigma$ dependences of moisture content $w$ for small-seeded lentil (1) and large-seeded lentil (2)

These increasing dependences can be also modelled by the power function:

$$
\sigma=\sigma_{0} w^{k}
$$

where:

$\sigma_{0} \quad$ - reference conductivity

k - constant

The coefficients of regression Eq. (10) and the coefficient of determination are displayed in Table 2.

Table 2 Coefficients of regression Eq. (10) and coefficient of determination

\begin{tabular}{|l||c|c|c|}
\hline Type of lentil & $\sigma_{0}$ in S·m & $\boldsymbol{k}$ & $\boldsymbol{R}^{\mathbf{1}}$ \\
\hline Small-seeded (1) & $1.10^{-5}$ & 0.4116 & 0.9956 \\
\hline Large-seeded (2) & $8.10^{-6}$ & 0.7987 & 0.9829 \\
\hline
\end{tabular}

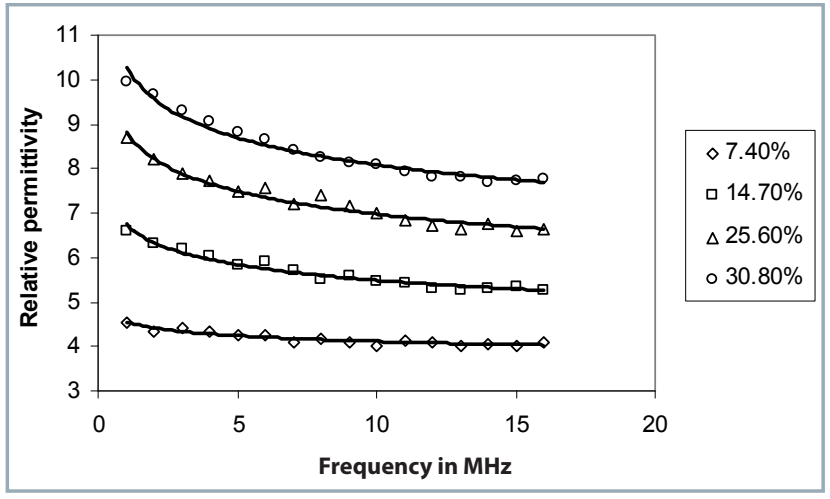

Fig. 2 Relative permittivity $\varepsilon_{r}$ dependences of frequency $f$ for small-seeded lentil samples of different moisture content $w$

Also the power function was used for modelling these dependences:

$$
\varepsilon_{r}=\varepsilon_{r 0}\left(\frac{f}{f_{0}}\right)^{k}
$$

where:

$\varepsilon_{r 0} \quad-$ reference relative permittivity

$k \quad-$ constant

$f_{0}=1 \mathrm{MHz}$ 
The coefficients of regression Eq. (11) and the coefficient of determination are displayed in Table 3.

Table 3 Coefficients of regression Eq. (11) and coefficient of determination

\begin{tabular}{|l||c|c|c|}
\hline Moisture content in \% & $\varepsilon_{\boldsymbol{r} \mathbf{0}}$ & $\boldsymbol{k}$ & $\boldsymbol{R}^{\mathbf{2}}$ \\
\hline $\mathbf{7 . 4}$ & 4.554 & -0.0442 & 0.8689 \\
\hline $\mathbf{1 4 . 7}$ & 6.7374 & -0.0891 & 0.9656 \\
\hline $\mathbf{2 5 . 6}$ & 8.8311 & -0.1024 & 0.9645 \\
\hline $\mathbf{3 0 . 8}$ & 10.285 & -0.1046 & 0.9706 \\
\hline
\end{tabular}

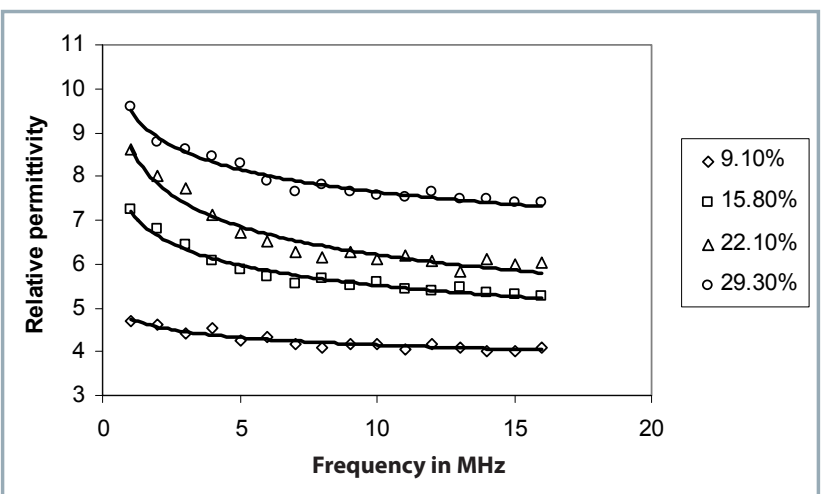

Fig. 3 Relative permittivity $\varepsilon_{r}$ dependences of frequency $f$ for large-seeded lentil samples of different moisture content $w$

Also the power function was used for modelling these dependences:

$$
\varepsilon_{r}=\varepsilon_{r 0}\left(\frac{f}{f_{0}}\right)^{k}
$$

where:

$$
\begin{aligned}
& \varepsilon_{r 0}-\text { reference relative permittivity } \\
& k-\text { constant } \\
& f_{0}=1 \mathrm{MHz}
\end{aligned}
$$

The coefficients of regression Eq. (12) and the coefficient of determination are displayed in Table 4.

Table 4 Coefficients of regression Eq. (12) and coefficient of determination

\begin{tabular}{|l||c|c|c|}
\hline Moisture content in \% & $\varepsilon_{r 0}$ & $\boldsymbol{k}$ & $\boldsymbol{R}^{\mathbf{2}}$ \\
\hline $\mathbf{9 . 1}$ & 4.7519 & -0.0586 & 0.8991 \\
\hline $\mathbf{1 5 . 8}$ & 7.2043 & -0.1163 & 0.9646 \\
\hline $\mathbf{2 2 . 1}$ & 8.6642 & -0.1448 & 0.9455 \\
\hline $\mathbf{2 9 . 3}$ & 9.4901 & -0.094 & 0.963 \\
\hline
\end{tabular}

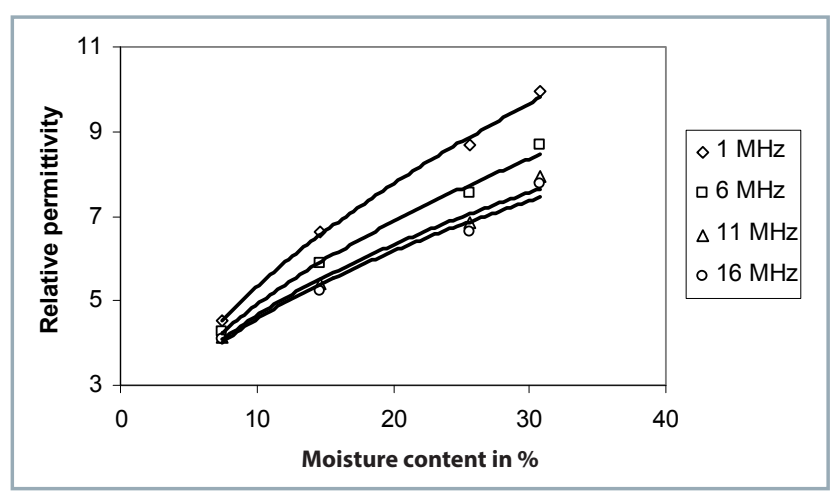

Fig. 4 Relative permittivity $\varepsilon_{r}$ dependences of moisture content $w$ for small-seeded lentil samples measured at different frequency $f$

Also the power function was used for modelling these dependences:

$$
\varepsilon_{r}=\varepsilon_{r 0} w^{k}
$$

where:

$\varepsilon_{r 0} \quad-$ reference relative permittivity

$k \quad$ - constant

The coefficients of regression Eq. (13) and the coefficient of determination are displayed in Table 5.

Table 5 Coefficients of regression Eq. (13) and coefficient of determination

\begin{tabular}{|l||c|c|c|}
\hline Frequency in $\mathbf{M H z}$ & $\varepsilon_{\boldsymbol{r} \mathbf{0}}$ & $\boldsymbol{k}$ & $\boldsymbol{R}^{\mathbf{2}}$ \\
\hline $\mathbf{1}$ & 1.5354 & 0.5409 & 0.9983 \\
\hline $\mathbf{6}$ & 1.612 & 0.4839 & 0.9957 \\
\hline $\mathbf{1 1}$ & 1.684 & 0.4415 & 0.9885 \\
\hline $\mathbf{1 6}$ & 1.6868 & 0.433 & 0.9831 \\
\hline
\end{tabular}

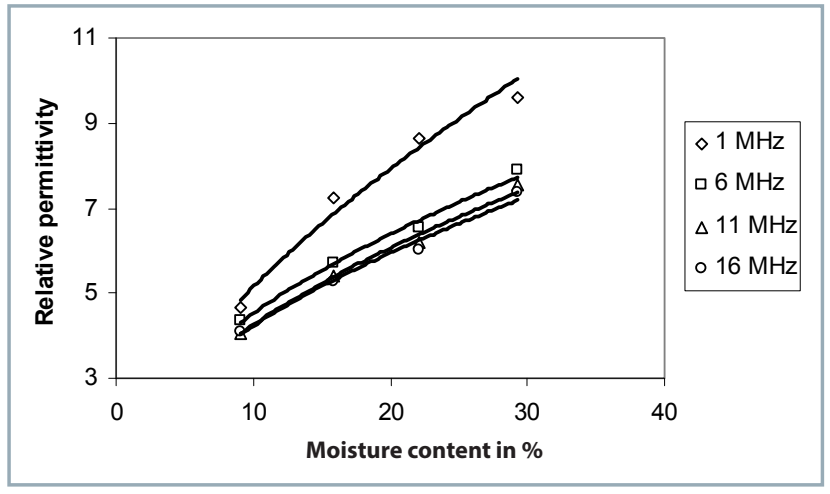

Fig. 5 Relative permittivity $\varepsilon_{r}$ dependences of moisture content $w$ for large-seeded lentil samples measured at different frequency $f$

Also the power function was used for modelling these dependences:

$$
\varepsilon_{r}=\varepsilon_{r 0} w^{k}
$$


where:

$\varepsilon_{r 0} \quad-$ reference relative permittivity

$k \quad$ - constant

The coefficients of regression Eq. (14) and the coefficient of determination are displayed in Table 6.

Table 6 Coefficients of regression Eq. (14) and coefficient of determination

\begin{tabular}{|l|c|c|c|}
\hline Frequency in $\mathbf{M H z}$ & $\varepsilon_{\boldsymbol{r} \mathbf{0}}$ & $\boldsymbol{k}$ & $\boldsymbol{R}^{\mathbf{2}}$ \\
\hline $\mathbf{1}$ & 1.2298 & 0.6219 & 0.9752 \\
\hline $\mathbf{6}$ & 1.4421 & 0.4969 & 0.9931 \\
\hline $\mathbf{1 1}$ & 1.3093 & 0.5117 & 0.9923 \\
\hline $\mathbf{1 6}$ & 1.3597 & 0.4926 & 0.988 \\
\hline
\end{tabular}

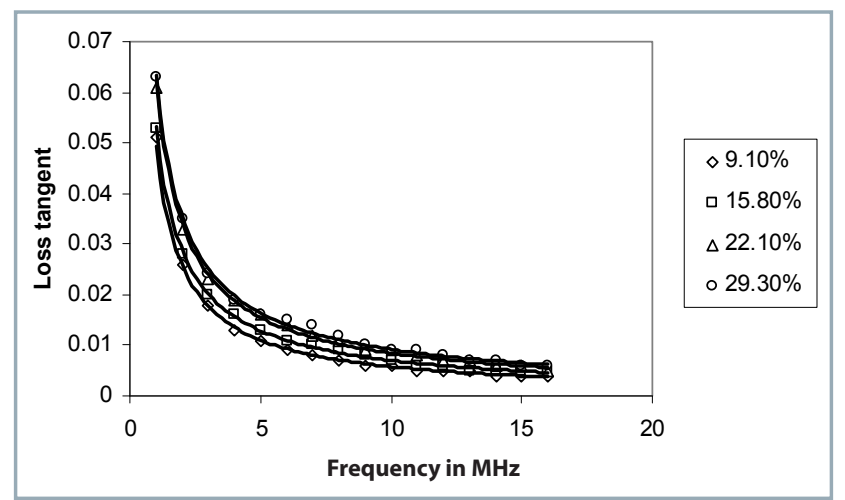

Fig. 6 Loss tangent $\operatorname{tg} \delta$ dependences of frequency $f$ for large-seeded lentil samples of different moisture content $w$

Also the power function was used for modelling these dependences:

$$
\operatorname{tg} \delta=\operatorname{tg} \delta_{0}\left(\frac{f}{f_{0}}\right)^{k}
$$

where:

$\operatorname{tg} \delta_{0}-$ reference loss tangent

$k$ - constant

$f_{0}=1 \mathrm{MHz}$

The coefficients of regression Eq. (15) and the coefficient of determination are displayed in Table 7.

Table 7 Coefficients of regression Eq. (15) and coefficient of determination

\begin{tabular}{|c|c|c|c|}
\hline Moisture content in \% & $\operatorname{tg} \delta_{\mathbf{0}}$ & $\boldsymbol{k}$ & $\boldsymbol{R}^{\mathbf{2}}$ \\
\hline 9.1 & 0.0492 & -0.9292 & 0.9962 \\
\hline 15.8 & 0.053 & -0.8789 & 0.9956 \\
\hline 22.1 & 0.0623 & -0.8663 & 0.9944 \\
\hline 29.3 & 0.0633 & -0.8374 & 0.9931 \\
\hline
\end{tabular}

\section{References}

BANSAL, N. - DHALIVAL, A. S. - KULDIP, S. M. 2016. Dielectric characterization of rapeseed (Brassica napus L.) from 10 to $3000 \mathrm{MHz}$. In Biosystems Engineering, vol. 143, pp. 1-8. 
KERTÉSZ, Á. - HLAVÁČOVÁ, Z. - VOZARY, E. - STAROŇOVÁ, L. 2015. Relationship between moisture content and electrical impedance of carrot slices during drying. In International Agrophysics, vol. 29, no. 1, pp. 61-66.

LAWRENCE, K. C. - NELSON, S. O. - KRASZEWSKI, A. 1990 Temperature dependence of dielectric properties of wheat. In Transactions of the ASAE, vol. 33, no. 2, pp. 535-540.

LAWRENCE, K. C. - NELSON, S. O. - KRASZEWSKI, A. 1992. Temperature dependence of dielectric properties of pecans In Transactions of the ASAE, vol. 35, no. 1, pp. 251-255.

NELSON, S. O. 1991. Correlating dielectric properties of solid and particulate sample through mixture relationship. In Transactions of the ASAE, vol. 35, no. 2, pp. 625-629.

NELSON, S. O. 1999. Dielectric properties measurement techniques and applications. In Transactions of the ASAE, vol. 42, no. 2, pp. 523-529.
NELSON, S. O. - GUO, W. - TRABELSI, S. - KAYS, S. J. 2007. Dielectric spectroscopy of watermelons for sensing quality. In Measurement Science and Technology, vol. 18, pp. 1887-1892.

PRIATKOVÁ, L. - HLAVÁČOVÁ, Z. - KERTÉSZ, Á. 2011. Electrical capacity and resistance measurement of blueberry cultivars (Vaccinium corymbosum L.). In Acta Technologica Agriculturae, vol. 14 , no. 2, pp. 32-35.

YOU, T. S. - NELSON, S. O. 1988. Microwave dielectric properties of rice kernels. In Microwave Power and Electromagnetic Energy, vol. 23, no. 3, pp. 150-159.

WEIR, W. B. 1974. Automatic measurement of complex dielectric constant and permeability at microwave frequencies. In Proceedings of the IEEE, vol. 62, no. 1, pp. 33-36. 